\title{
Complexation of Group 12 Transition Metals by Methanobactins from Methylocystis sp. strain SB2
}

PETER ECKERT ${ }^{1}$, ALEXANDER JOHS ${ }^{1}$, JEREMY SEMRAU $^{2}$, ALAN DISPIRITO $^{3}$, JOCELYN RICHARDSON ${ }^{4}$, RITIMUKTA SARANGI ${ }^{5}$, BAOHUA GU ${ }^{1}$ AND ERIC PIERCE $^{1}$

${ }^{1}$ Oak Ridge National Laboratory

${ }^{2}$ University of Michigan

${ }^{3}$ Iowa State University

${ }^{4}$ Stanford Synchrotron Radiation Lightsource

${ }^{5}$ Stanford Synchrotron Radiation Lightsource, SLAC National Accelerator Laboratory

Presenting Author: eckertpa@ornl.gov

Methanotrophic bacteria activate methane using enzymes with $\mathrm{Cu}$-based active sites and excrete small peptides known as methanobactins as part of an extracellular copper acquisition system analogous to that of siderophores for iron. In addition to copper, methanobactin peptides have been shown to interact strongly with the Group 12 transition metals, and thus represent a convergence between their biogeochemical cycles and the biogeochemical methane cycle. We characterize the complexation of $\mathrm{Zn}^{2+}, \mathrm{Cd}^{2+}$, and $\mathrm{Hg}^{2+}$ by methanobactins excreted by methylocystis sp. strain SB2 using spectroscopic and computational methods, and propose a molecular mechanism for a significant fluorescence enhancement observed upon complexation of $\mathrm{Zn}^{2+}$ and $\mathrm{Cd}^{2+}$ by mb-SB2. We draw upon our spectroscopic data to probe the competitive complexation interactions of methanobactins and other classes of ligands for the Group 12 transition metals and note the trends in ligand competition for the transition metal ions. Our work represents the first computational investigation of methanobactins and their organometallic complexes and sheds new light on the molecular interactions which may modulate their extracellular impact on the speciation and transport of the Group 12 transition metals. 